\title{
VOLUME OR POSITION CHANGES OF PRIMARY LUNG TUMOR DURING (CHEMO-)RADIOTHERAPY CANNOT BE USED AS A SURROGATE FOR MEDIASTINAL LYMPH NODE CHANGES: THE CASE FOR OPTIMAL MEDIASTINAL LYMPH NODE IMAGING DURING RADIOTHERAPY
}

Citation for published version (APA):

van Elmpt, W., Ollers, M., van Herwijnen, H., den Holder, L., Vercoulen, L., Wouters, M., Lambin, P., \& De Ruysscher, D. (2011). VOLUME OR POSITION CHANGES OF PRIMARY LUNG TUMOR DURING (CHEMO-)RADIOTHERAPY CANNOT BE USED AS A SURROGATE FOR MEDIASTINAL LYMPH NODE CHANGES: THE CASE FOR OPTIMAL MEDIASTINAL LYMPH NODE IMAGING DURING RADIOTHERAPY. International Journal of Radiation Oncology Biology Physics, 79(1), 89-95. https://doi.org/10.1016/j.jijrobp.2009.10.059

Document status and date:

Published: 01/01/2011

DOI:

10.1016/j.jijrobp.2009.10.059

Document Version:

Publisher's PDF, also known as Version of record

Document license:

Taverne

Please check the document version of this publication:

- A submitted manuscript is the version of the article upon submission and before peer-review. There can be important differences between the submitted version and the official published version of record.

People interested in the research are advised to contact the author for the final version of the publication, or visit the DOI to the publisher's website.

- The final author version and the galley proof are versions of the publication after peer review.

- The final published version features the final layout of the paper including the volume, issue and page numbers.

Link to publication

\section{General rights}

Copyright and moral rights for the publications made accessible in the public portal are retained by the authors and/or other copyright owners and it is a condition of accessing publications that users recognise and abide by the legal requirements associated with these rights.

- Users may download and print one copy of any publication from the public portal for the purpose of private study or research. - You may not further distribute the material or use it for any profit-making activity or commercial gain

- You may freely distribute the URL identifying the publication in the public portal.

If the publication is distributed under the terms of Article 25fa of the Dutch Copyright Act, indicated by the "Taverne" license above, please follow below link for the End User Agreement:

www.umlib.nl/taverne-license

Take down policy

If you believe that this document breaches copyright please contact us at:

repository@maastrichtuniversity.nl

providing details and we will investigate your claim. 


\title{
VOLUME OR POSITION CHANGES OF PRIMARY LUNG TUMOR DURING
} (CHEMO-)RADIOTHERAPY CANNOT BE USED AS A SURROGATE FOR MEDIASTINAL LYMPH NODE CHANGES: THE CASE FOR OPTIMAL MEDIASTINAL LYMPH NODE IMAGING DURING RADIOTHERAPY

\author{
Wouter van Elmpt, Ph.D., Michel Öllers, Ph.D., Henrieke van Herwijnen, B.Health, \\ Linda den Holder, B.Health, Lindsay Vercoulen, B.Health, Monique Wouters, B.Health, \\ Philippe Lambin, M.D., Ph.D., and Dirk De Ruysscher, M.D., Ph.D. \\ Department of Radiation Oncology (MAASTRO), GROW-School for Oncology and Developmental Biology, Maastricht University \\ Medical Centre, Maastricht, The Netherlands
}

\begin{abstract}
Purpose: Primary lung tumors can be visualized mostly with cone beam computed tomography (CT), whereas visualization is much more difficult for mediastinal lymph nodes (LN). If the volumetric and positional changes of the primary tumor could be used as a surrogate for the LN, this would facilitate image-guided radiotherapy. The purpose of this study was to investigate the relationship between the positional and volumetric changes in primary tumors and the involved LN during (chemo)radiotherapy treatment of non-small-cell lung cancer patients. Methods and Materials: $\left[{ }^{18}\right.$ F]fluorodeoxyglucose positron emission tomography/computed tomography imaging was performed before radiotherapy and in the second week of treatment in 35 patients. Gross tumor volumes (GTV) of the primary tumor (GTVprim) and of the involved LN (GTVlymph) were delineated. Changes in position and volume of GTVprim with respect to GTVlymph and the bony anatomy were compared.

Results: In individual cases, large displacements up to $1.6 \mathrm{~cm}$ and volume changes of $50 \%$ of the primary tumor may occur that are not correlated to the changes in involved LN. The volume of GTVprim reduced, on average, by $5.7 \% \pm 19.0 \%$ and was not correlated with the small increase of $1.4 \% \pm 18.2 \%$ in involved LN volume. Compared to bony anatomy, displacement of the primary tumor was statistically correlated to the involved LN displacement. Conclusions: Volume and position changes of the primary tumor are not always predictive for LN changes. This suggests that for characterization of involved LN, repeated state-of-the-art mediastinal imaging during radiotherapy may be necessary. (C) 2011 Elsevier Inc.
\end{abstract}

Non-small-cell lung cancer, Mediastinal lymph nodes, Volume quantification, Tumor position, Repeated imaging.

\section{INTRODUCTION}

Treatment for inoperable non-small-cell lung cancer (NSCLC) is radiotherapy, performed mostly with either sequential or concurrent chemotherapy. Both radiotherapy and chemotherapy may influence the tumor volume during the therapy (1-6). Moreover, baseline positional changes of the primary tumor have also been described (7-9). As a consequence, the radiotherapy treatment plan derived at a certain point prior to treatment might not be optimal for these changes in anatomy during therapy. In such a treatment plan typically both the primary tumor and the involved lymph nodes are irradiated (10). A shift of location between the primary tumor and the lymph nodes might affect the accuracy of the treatment delivery and hence treatment outcome.
The recent use of in-room volumetric imaging techniques such as $\mathrm{kV}$ and MV cone-beam computed tomography (CT) or the MV CT at the tomotherapy machine has given a vast amount of information for the primary tumor (1-6). Volumetric changes of the primary tumor of NSCLC patients are frequently described. For example, Fox et al. (2) showed by using repeated CT imaging that for NSCLC, the gross tumor volume (GTV) reduced up to $24 \%$ and $44 \%$ after 30 and 50 Gy, respectively. Others described similar numbers for GTV reduction during treatment $(1,3,5,11)$.

Information about the evolution of volumes and positional changes for the lymph nodes is less well described. Pantarotto et al. (12) investigated the intrafraction motion of the lymph nodes and compared the motion to that of the primary tumor and showed that phase differences may occur.
Reprint requests to: Wouter van Elmpt, $\mathrm{PhD}$, Department of Radiation Oncology (MAASTRO clinic), GROW - School for Oncology and Developmental Biology, Maastricht University Medical Centre, Dr. Tanslaan 12, NL-6229 ET Maastricht, The Netherlands. Tel: 31884455 666; Fax: 31884455 667; E-mail: wouter.vanelmpt@maastro.nl
This study was performed within the framework of the Center for Translational Molecular Medicine (www.ctmm.nl), project AIRFORCE number 03O-103.

Conflict of interest: none.

Received Aug 18, 2009, and in revised form Oct 8, 2009. Accepted for publication Oct 23, 2009. 
Bosmans et al. $(4,5)$ described the time trend of both volume changes in the primary tumor and the motion of the mediastinal lymph nodes and showed a large heterogeneity in volume changes during the course of radiotherapy for both primary tumor and nodal volume. However, they did not investigate the relationship between the displacement of the primary tumor and the lymph nodes.

Most of the studies describing changes in primary tumor volume use currently available in-room volumetric imaging techniques at the treatment machine such as cone beam CT imaging. These techniques, however, are less suitable for visualization of the involved lymph nodes. Lymph node structures are poorly visible on current in-room imaging modalities, and assessment of volumetric or functional changes in these structures is thus not straightforward using these in-room imaging technologies. Therefore, we have chosen to use the best diagnostic imaging method, also considered the current state of practice for performing treatment preparation and planning: four-dimensional (4D) CT imaging, preferably including $\left[{ }^{\mathbf{1 8}} \mathbf{F}\right]$ fluorodeoxyglucose positron emission tomography (FDG PET) imaging, using a PET/ CT scanner. This is the only method currently available to accurately analyze both volume and position variations during treatment of both the primary tumor and the lymph nodes.

During a fixed period of time, we prospectively imaged all our lung cancer patients in the second week of treatment, using the same diagnostic imaging procedure as used for treatment planning: FDG-PET for functional information combined with contrast-enhanced CT imaging. On these scans, the tumor volumes are delineated and compared to the planning PET/CT scan. In this report, we investigated the relationship between volumetric and positional changes of the primary tumor and the involved mediastinal lymph nodes induced by (chemo-)radiotherapy during the first week of treatment.

\section{METHODS AND MATERIALS}

\section{Patient characteristics}

We prospectively acquired 4D respiratory-correlated (RC) CT images with a 3D FDG PET image and a 3D CT scan, using an intravenous contrast medium of NSCLC patients treated between September 2008 and December 2008 according to our clinical protocol.

\section{Image acquisition and treatment protocol}

4D CT images were acquired for all patients, using our standard $4 \mathrm{D}$ RC CT imaging protocol. From this $4 \mathrm{D}$ CT scan, the $50 \%$ exhale phase, closely corresponding to the average position of the tumor, was chosen for delineation and treatment planning. The other phases of the 4D scan are currently not used in treatment planning. A 3D FDG PET scan of the thorax as well as a 3D CT with iodine-based IV contrast (XENETIX 300; Guerbet, Aulnay-sous-Bois, France) was acquired after making the 4D RC CT scan. The 50\% exhale CT scan and 3D FDG-PET scan are used in the delineation process of the tumor volume and normal tissues. Afterward, a 3D conformal treatment plan was designed according to the clinically used doseescalation protocol for the specific patient. For the group receiving no chemotherapy or induction chemotherapy, followed by radiotherapy, a dose escalation protocol was used based on normal tissue constraints up to 79.2 Gy with twice daily fraction sizes of $1.8 \mathrm{~Gy}$ $(13,14)$. For patients receiving concurrent chemoradiotherapy, a twice daily dose escalation protocol of 1.5 Gy per fraction was used for the first 30 fractions, and afterwards, a dose escalation up to $69 \mathrm{~Gy}$, based on normal tissue toxicity, was performed in a daily fraction size of $2.0 \mathrm{~Gy}$.

In the second week of radiotherapy treatment, around the 8th day after the start of radiotherapy, a second ${ }^{18}$ F-FDG PET/CT scan was acquired using the same protocol as for the planning CT scan. The patient was positioned at the CT couch using the same set-up as that used during the planning CT scan and during treatment, using patient immobilization devices, skin markers, and the laser lines as reference.

The GTVs of the primary tumor and involved lymph nodes were copied from the planning CT scan to the repeated CT scan. Afterward, these structures were edited to represent the volumes of the repeated data set. Also, the lungs were delineated on the repeated data set.

\section{Image registration procedure}

The datasets of the planning CT scan were manually registered with those of the CT scan during treatment by using a rigid registration. Of the rigid registration, only translations were allowed to mimic the situation on the treatment machine, where only couch translations are possible. This visual registration was based on the bony anatomy of the entire anatomy around the primary tumor and the involved mediastinal lymph nodes. This registration was performed by at least 2 persons, and the mean value of these registration values was used.

\section{Gross tumor and lymph node volume analysis}

For both the primary tumor and the involved mediastinal lymph nodes, the volume was calculated on the planning CT scan and on the repeated CT scan during treatment. Differences were also classified according to the chemotherapy scheme, i.e., induction chemotherapy followed by radiotherapy, concurrent chemoradiotherapy, or no chemotherapy.

\section{Gross tumor and lymph node displacements}

After the registration of the planning CT scan with the CT scan during treatment, the displacement between the GTV during planning and treatment was calculated using the coregistration matrix using the mid-points of both GTVs. The evaluation of the displacement for the involved lymph nodes, if present, was also performed.

The distance between the GTV of the primary tumor and the involved lymph nodes was also calculated and compared to the distance at the repeated CT scan during treatment.

Although deformations of the primary tumor are not expected due to breathing (15), we wanted to exclude the fact that baseline displacements are influenced by a different phase in the breathing cycle. The total lung volume of the $50 \%$ exhalation of the 4D CT scan was compared in both CT scans as an easily used substitute to check whether both CT scans were made during the same breathing phase.

\section{Statistical evaluation}

Statistical significance for paired results was evaluated using a Wilcoxon signed-rank test; for nonpaired results, the Mann-Whitney $U$ test was performed. Correlation between parameters was assessed using linear regression, and 95\% confidence intervals (CI) are 
given. Analysis was performed using SPSS software (version 15.0; Chicago, IL). Fractional volume differences are defined as (V2 V1)/V1 $\times 100 \%$, where V1 and V2 are the GTV volumes of the planning and of the repeated dataset, respectively. Results are presented as mean values \pm 1 standard deviation. Differences are assumed to be statistically significant for $p$ values smaller than 0.05 .

\section{RESULTS}

\section{Patient characteristics}

A total of 35 patients were imaged before radiotherapy and during the second week of radiotherapy. One patient had two primary tumors inside the lung; this patient was counted twice in the analysis of the primary tumor statistics and once for the lymph node involvement. In one patient, the GTV could not be accurately delineated on the repeated PET/CT scan and was excluded from further analysis. An overview of patient characteristics is shown in Table 1.

The average time between the planning PET/CT scan and the repeated PET/CT scan was $17.1 \pm 3.0$ days (range, 11 to 24 days), the average time between first radiotherapy fraction and repeated scan was $8.6 \pm 1.8$ days (range, 6 to 13 days). The average number of fractions delivered was 13.1 \pm 2.7 (range, 8 to 19 fractions), with a delivered dose up to the repeated scan of an average $20.7 \pm 4.8$ Gy (range, 12.0 to $34.2 \mathrm{~Gy}$ ).

Table 1. Patient characteristics

\begin{tabular}{lcc}
\hline Characteristic & Parameter & Value \\
\hline Gender & Male & 24 \\
& Female & 10 \\
Age (years) & Mean (SD) & $64.2(9.3)$ \\
Stage & Range & $45-81$ \\
& I-II & $3^{*}$ \\
& IIIa & 14 \\
IIIb & 16 \\
Chemotherapy & IV & 2 \\
& Induction & $18^{\dagger}$ \\
& chemotherapy & \\
Concurrent & 14 \\
primary tumor & chemotherapy & 2 \\
& No chemotherapy & 15 \\
& RUL* & 2 \\
& RML & 8 \\
& RLL & 7 \\
Lymph nodes & LUL* & 2 \\
involved & LLL & 1 \\
& Mediastinal & 9 \\
& node 4 & 25 \\
\hline & No & \\
& Yes & \\
& &
\end{tabular}

Abbreviations $:$ RUL = right upper lobe; $\mathrm{RML}=$ right middle lobe; $\mathrm{RLL}=$ right lower lobe; LUL = left upper lobe; LLL = left lower lobe.

* This includes the patient with two primary tumors classified as stage Ia and IIb.

${ }^{\top}$ Two patients had only 1 cycle of induction chemotherapy.
Fourteen patients had received concurrent chemoradiotherapy, 19 patients had at least 1 cycle of induction chemotherapy ( 2 patients had only a single cycle, the other patients had 3 cycles), and 2 patients did not have chemotherapy.

\section{Volume primary tumor}

For all analyzed primary tumors $(n=35)$, a statistically significant decrease in tumor volume, from $59.8 \pm 56.7 \mathrm{~cm}^{3}$ to $54.9 \pm 49.3 \mathrm{~cm}^{3}$, a reduction of $4.8 \pm 13.4 \mathrm{~cm}^{3}$ (range, -43.0 to $+17.4 \mathrm{~cm}^{3}, p=0.015$ ) was observed for the planning CT scan and the repeated CT scan, respectively. The average fractional volume reduction was $5.7 \% \pm 19.0 \%$ (range, $-66 \%$ to $+47 \%$ ) over all primary tumors. For 25 patients, a volume reduction was observed, and 9 patients showed an increase in volume (Fig. 1.).

For the concurrent chemoradiotherapy patients $(n=15)$, the volume of the primary tumor decreased, on average, by $6.2 \pm 17.2 \mathrm{~cm}^{3}(p=0.281)$ from $80.0 \pm 69.7 \mathrm{~cm}^{3}$ to 73.8 $\pm 60.7 \mathrm{~cm}^{3}$, the average fractional volume reduction this group was $1.1 \% \pm 20.2 \%$ (range, $-29 \%$ to $47 \%$ ). For the group of patients receiving induction chemotherapy followed by radiotherapy $(n=18)$, these values were $46.0 \pm 42.0 \mathrm{~cm}^{3}$ to $42.4 \pm 35.3 \mathrm{~cm}^{3},\left(3.4 \pm 10.4 \mathrm{~cm}^{3}\right.$; range, -41.0 to +11.1 $\left.\mathrm{cm}^{3}, p=0.025\right)$, with an average fractional volume reduction of $7.8 \% \pm 18.3 \%$, ranging from -66 to $+24 \%$. Two patients $(n=2)$ received no chemotherapy and showed a volume reduction from the planning CT scan of 30.8 and $32.9 \mathrm{~cm}^{3}$ to the repeated CT scan of $23.6(23 \%)$ and $26.9(-18 \%) \mathrm{cm}^{3}$, respectively. The induction chemotherapy group showed a larger but nonsignificant decrease in volume compared to the concurrent chemotherapy group ( $p=0.828)$.

\section{Volume mediastinal lymph nodes}

Over the entire patient population with involved mediastinal lymph nodes $(n=25)$, no significant difference in lymph node volume was observed $(p=0.670), 28.1 \pm 32.8 \mathrm{~cm}^{3}$ to $29.2 \pm 36.0 \mathrm{~cm}^{3}$ for the planning CT scan and the repeated CT scan, respectively (Fig. 1). Sixteen patients showed a decrease: an increase in volume in 7 patients, and for 1 patient the volume remained stable. Fractional volume differences showed no significant decrease in lymph node volume ( $p=0.378 ;-1.4 \% \pm 18.2 \%$, ranging from $61 \%$ to $+35 \%$ )

The changes in volume from the planning to the repeated CT scans of the primary tumor did not correlate with changes in lymph node volume, as shown in Fig. 2. Linear regression did not show a statistically significant difference $(p=0.581)$ for the relative changes (Fig. 2) or $(p=0.154)$ for the absolute changes in volume (data not shown).

\section{Deformation primary tumor and distance to mediastinal lymph nodes}

Analysis of the total lung volume on the CT scan measured prior to and during treatment showed no statistically significant difference $(p=0.145)$, implying that the breathing phases are approximately equal between the time points and that no additional deformation or baseline shifts due to breathing are expected. 

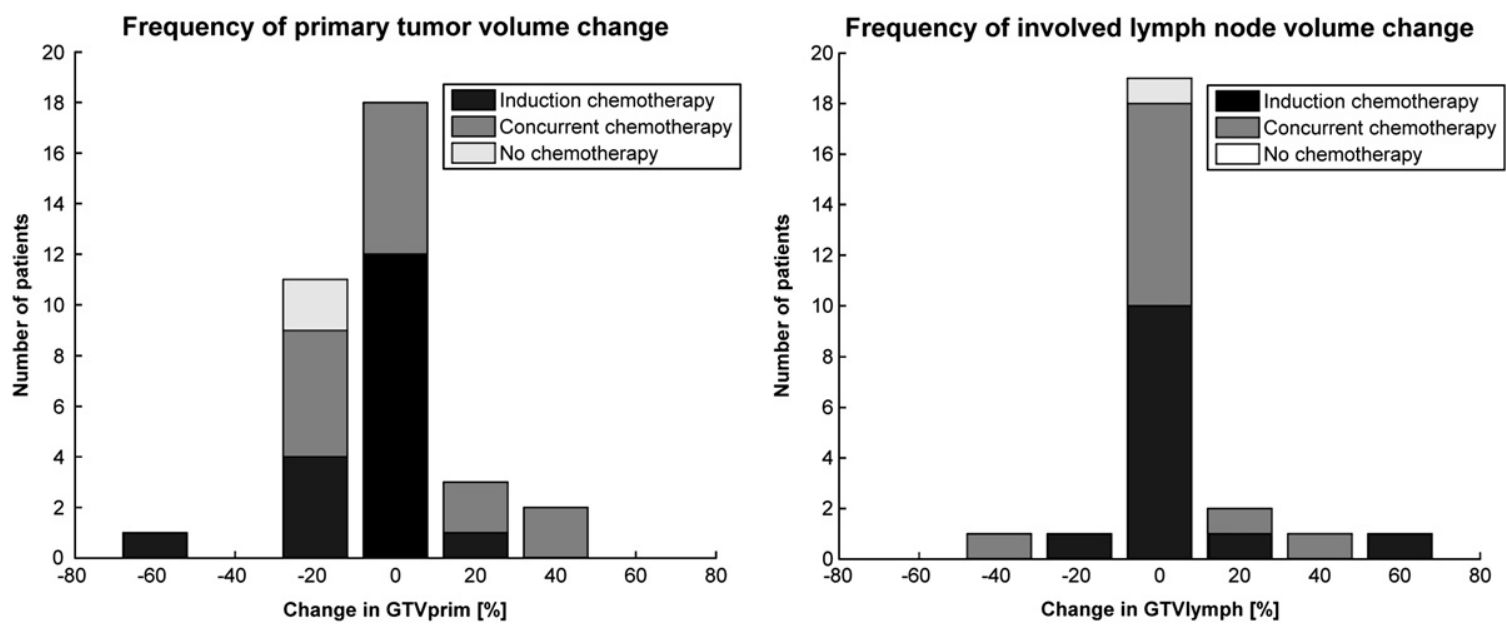

Fig. 1. Frequency of the relative changes in volume of the primary tumor (GTVprim) (left panel) and the relative changes in volume of the involved lymph nodes (GTVlymph) (right panel). Bars represent an interval of 20\%, e.g., $0 \%$ represents changes from $-10 \%$ to $+10 \%$.

The distance between the center of the primary tumor on the planning CT scan was compared with the center on the repeated CT scan during treatment. A mean displacement of $5.6 \pm 4.0 \mathrm{~mm}$ was observed in a range of $0.8 \mathrm{~mm}$ up to a maximum displacement of $15.8 \mathrm{~mm}$. Eleven (31\%) patients showed displacements larger than $5 \mathrm{~mm}$, and for $25(74 \%)$ patients, the displacement was greater than $3 \mathrm{~mm}$. No statistical difference in primary tumor displacement between the concurrent and the induction chemotherapy group was observed $(p=0.532)$.

No correlation of the primary tumor displacement and relative $(p=0.458)$ or absolute $(p=0.815)$ volume change of the primary tumor was found (Fig. 3). Also, for the relative $(p=0.358)$ and absolute $(p=0.461)$ involved lymph node, volume changes, and lymph node displacement, no statistically significant differences were observed.

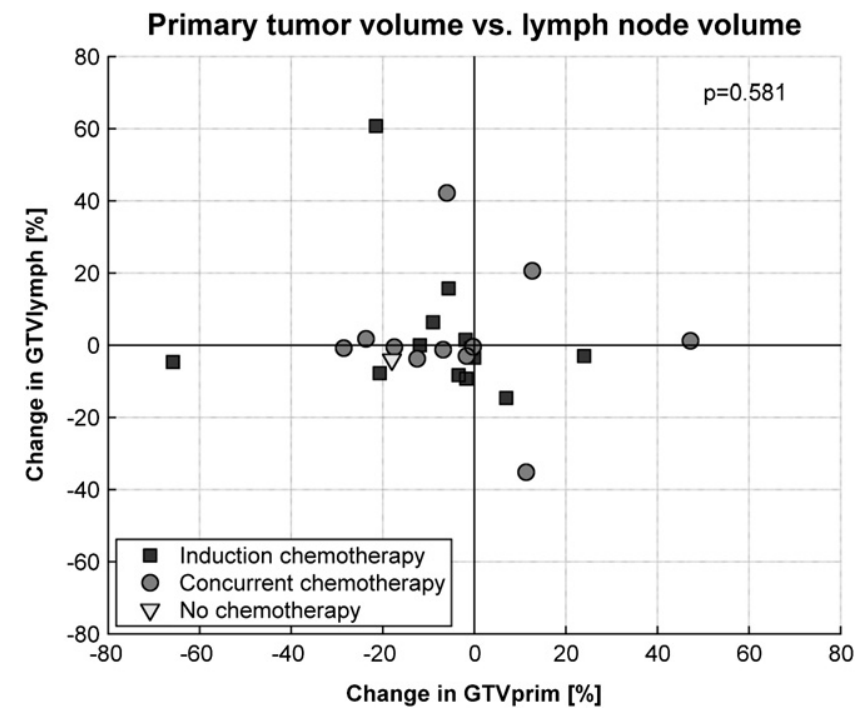

Fig. 2. Relative changes in volume of the primary tumor (GTVprim) and the relative change in volume of the lymph nodes (GTVlymph). The changes in GTVprim and GTVlymph were not correlated $(p=0.581)$.
The position of the lymph nodes on the planning CT scan was compared to the position of the nodes on the repeated CT scan during treatment. For the lymph nodes grouped per patient (on average, $2.5 \pm 1.6$; range, 1 to 6 lymph nodes were involved), a mean displacement of $4.2 \pm 2.5 \mathrm{~mm}$ (range, $1-$ $11 \mathrm{~mm})$ was observed. For more than half $(60 \%)$ of these patients ( 15 out of 25 ), the displacement between the bony anatomy and the involved lymph nodes was larger than 3 $\mathrm{mm}$, and in 24\% (6 out of 25) patients, a displacement of more than $5 \mathrm{~mm}$ was observed.

The distance between the primary tumor and the average center of the involved mediastinal lymph nodes (GTVlymph) did not change significantly ( $p=0.797$ ) between the planning and the repeated CT scan during treatment, $0.4 \pm 2.6 \mathrm{~mm}$ (range, -3.5 to $+8.6 \mathrm{~mm}$ ). Although, again, for a single patient, a displacement of the center of the primary tumor compared to the center of the lymph nodes was $9 \mathrm{~mm}$, caused predominantly by a large shrinkage of the primary tumor, of which the midpoint shifted 16 $\mathrm{mm}$. This large shift was partly compensated due to a displacement of the center of the lymph nodes toward the center of the primary tumor.

The displacement of the primary tumor could be related to the displacement of the lymph nodes, although the correlation was weak (Fig. 4). Linear regression showed a significant slope parameter for the left-right direction, $0.36 \mathrm{~mm}(95 \% \mathrm{CI}$, $\left.0.08-0.65 ; r^{2}=0.235 ; p=0.014\right)$; anteroposterior direction, $0.68 \mathrm{~mm}\left(95 \% \mathrm{CI}, 0.47-0.89 ; r^{2}=0.664 ; p<0.001\right)$; and cranial-caudal direction, $0.27 \mathrm{~mm}(95 \% \mathrm{CI}=0.02-0.52$; $\left.r^{2}=0.182 ; p=0.034\right)$. The intercept parameter was not significant for these directions. The total displacement (length of the $3 \mathrm{D}$ vector) showed a significant relationship: a slope of $0.40\left(95 \% \mathrm{CI}=0.17-0.62 ; r^{2}=0.365 ; p=0.001\right)$ with an intercept of $2.1 \mathrm{~mm}(\mathrm{CI}=0.7-3.6 \mathrm{~mm}, p=0.007)$.

If the registration of both datasets was performed based on the center of the primary tumor (a primary tumor matching instead of bony anatomy), the mean displacement of the center of the involved lymph nodes was reduced slightly. For 

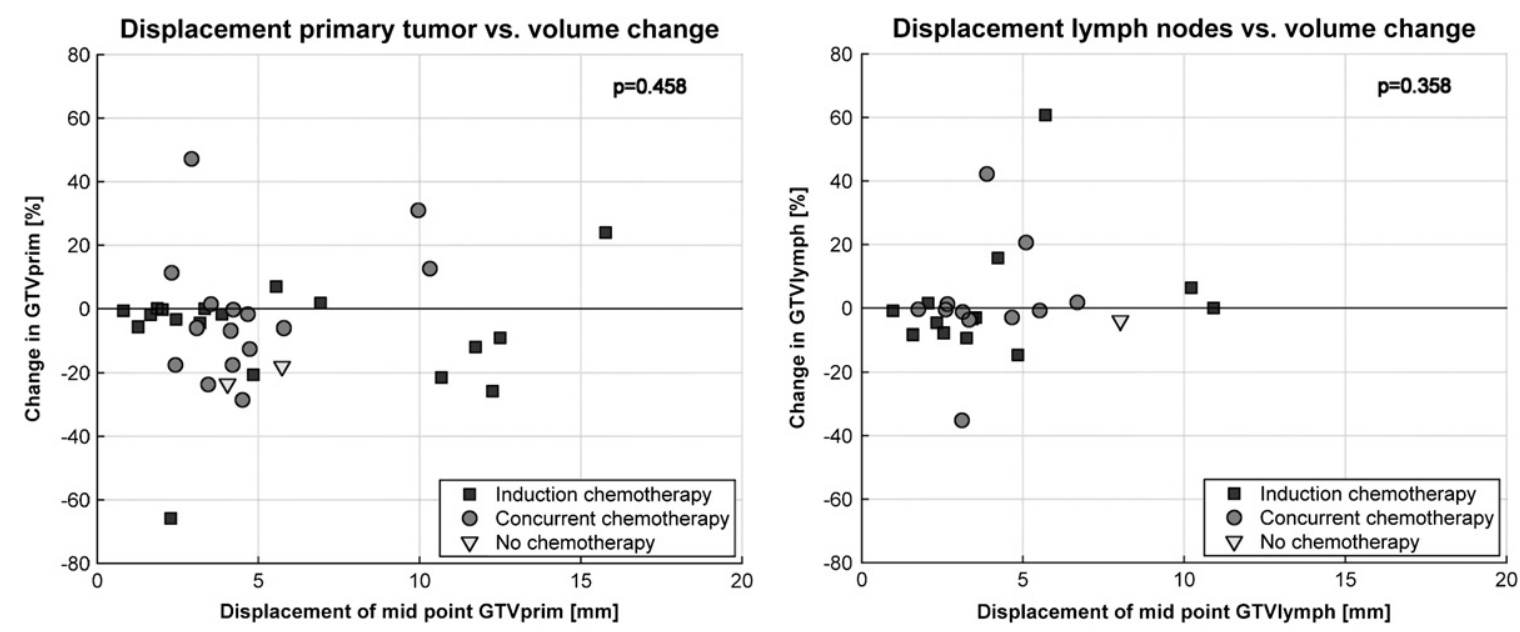

Fig. 3. The maximum displacement of the primary tumor GTVprim (left panel) and the lymph nodes GTVlymph (right panel) versus the relative change in volume.

$48 \%$ (12 of 25) of the patients, the displacement of the lymph nodes was larger than $3 \mathrm{~mm}$ and was more than $5 \mathrm{~mm}$ for $20 \%$ (5 of 25) of patients, compared to 60\% (15 of 24) and $24 \%$ (6 of 24), respectively, for the bony anatomy registration. In 8 patients (32\%), the distance in lymph node position increased more than $1 \mathrm{~mm}$ between if the registration was performed on the primary tumor instead of the bony anatomy, 8 patients (32\%) showed a decrease in displacement of more than $1 \mathrm{~mm}$, and in $9(36 \%)$ patients the displacement was within $1 \mathrm{~mm}$.
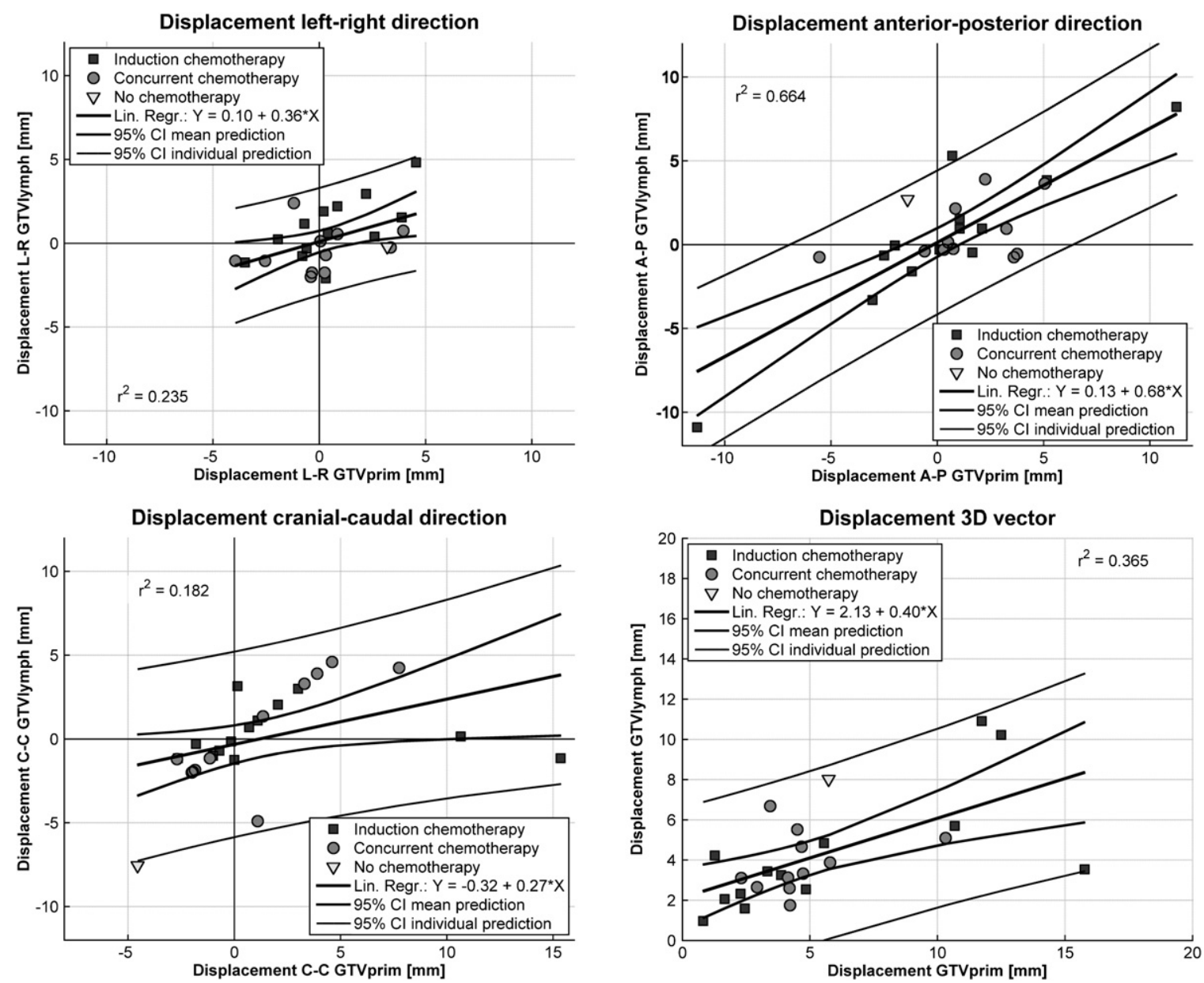

Fig. 4. Displacement of the primary tumor and involved lymph nodes for the left-right (upper left panel), anterior-posterior (upper right panel), and cranial-caudal (lower left panel) directions. In the lower right panel, the absolute displacement is shown. Linear regression has been performed, and the 95\% CI of the mean and individual predictions are also shown. 


\section{DISCUSSION}

Looking at individual patients, large displacements up to $1.6 \mathrm{~cm}$ for the center of the primary tumor compared to the bony anatomy were observed. For this patient, the volume increased by $24 \%$ compared to the planning CT scan, which explains that it was a tumor volume change causing this large displacement. The displacement of the lymph nodes at the two time points was smaller compared to that of the primary tumor, probably due to the fact that the registration is performed on the bony anatomy, which is closer to the anatomical site of the lymph nodes than to the primary tumor.

Patients receiving chemotherapy prior to radiotherapy showed a larger volume reduction than the concurrent radiotherapy group. Although the total number of patients $(n=35)$ is too small to divide the patients into subgroups for a thorough statistical analysis, an estimate is shown for the magnitude and frequency of the expected changes.

We could not detect any significant correlations between volume changes observed in the primary tumor and volume changes in the lymph nodes. This implies that if one wants to characterize changes in lymph node volume, the primary tumor cannot be used as a surrogate. We believe that repeated imaging using PET/CT equipment is a more accurate way of performing volumetric image analysis for our lung cancer patient group than cone beam CT or standard noncontrast-enhanced CT imaging. The availability of PET imaging for the functional imaging part of defining the tumor in case of mediastinal involvement in the GTV and the use of intravenous contrast for accurate delineation are necessary to quantify the volumetric and anatomical (and with ${ }^{18} \mathrm{~F}$-FDG or hypoxia PET imaging even functional) changes in the patient during (chemo)radiotherapy. For accurate quantification of volume and shape changes, the use of repeated PET/CT imaging also excludes possible errors and interpretation differences introduced by cross-modality comparative studies, such as cone-beam vs. diagnostic CT imaging. We focused in this study on repeated imaging already performed early on during treatment, i.e., after $\pm 20 \mathrm{~Gy}$. The main reason for this is that if changes and displacements can be quantified in the beginning of the treatment where there is still room for adaptation of the treatment plan. However, performing this study with repeated PET/CT imaging later during treatment, correlations might become statistically significant but at the cost that adaptation or changes to the treatment plan only affect the last fractions of treatment, and therefore no large therapeutic gain can be achieved in the remaining fractions. If the normal tissues allow some extra dose escalation, an additional boost of the residual tumor mass or residual high FDG-uptake pattern could be considered as an option for improving local control (3).

Displacement of the primary tumor and the involved lymph nodes related to the bony anatomy showed a statistically significant correlation, although this correlation was weak, as indicated by the small correlation coefficient, $r^{2}$, values that range between 0.18 to 0.66 . The higher correlation of a subset of cranial-caudal data points in Fig. 4 are due to course spacing of $3 \mathrm{~mm}$ of the CT slices in cranial-caudal direction, because the delineated structures are copied from the planning CT scan and adapted to the anatomy in the repeated CT scan generally resulting in the same number of delineated slices and hence the same center of mass of the delineated lymph nodes in the cranial-caudal direction. On average, the lymph nodes moved less than the primary tumor as indicated by a slope of linear regression ranging from 0.3 to 0.7 .

However, if we look at the scattering of the data points, also described by the low correlation coefficient $r^{2}$, and calculate the width of the $95 \% \mathrm{CI}$ around the slope parameter for the individual prediction, this typically ranges between 6 and $11 \mathrm{~mm}$. This makes accurate prediction for the individual patient of the lymph node displacement based on the primary tumor displacement difficult. Hence, one cannot make any reliable assumptions on the lymph nodes for the individual patient that are derived from characteristics of the primary tumor. An approach aiming at reduction of the planning tumor volume margins of the lymph nodes is not possible using information about the primary tumor.

Whereas we have shown one has to be cautious in using the primary tumor as a surrogate for the lymph node changes, other adaptation strategies are available by using repeated PET/CT imaging during treatment. In case of large volume reduction of the primary tumor, shrinking field techniques have been suggested to escalated dose values to the primary tumor. $(3,16,17)$. Another possibility is to boost the persistently high ${ }^{18}$ F-FDG-uptake regions, as these are hypothesized to be the more radio-resistant regions(18) or are even described as the region where local recurrences occur $(19,20)$. Boosting these regions might improve local control and hence overall survival.

The current trend in image-guided radiotherapy is to improve the patient setup by using a soft tissue registration approach of the primary tumor instead of the bony anatomy. This procedure might be beneficial for the patient in whom only the primary lung tumor is irradiated because margin reduction strategies can then be applied $(7,21,22)$. However, if the treatment plan also irradiates the involved mediastinal lymph nodes, one has to be very cautious because the displacement of the primary tumor might not be a surrogate for the displacement of the lymph nodes. A situation where the displacement of the primary tumor is opposite to the lymph node displacement deteriorates the dose coverage of the lymph nodes, including a higher probability of geometric miss. Current in-room (cone beam) CT imaging might not be suitable for characterizing the involved lymph nodes, and repeated state-of-the-art mediastinal PET/CT imaging during radiotherapy is necessary.

\section{CONCLUSIONS}

Repeated PET/CT imaging is necessary to assess the volume changes in the primary tumor and the lymph nodes. Even early during treatment, volume changes and positional variation may occur that may be large for an individual 
patient. On a population level, no large differences are observed, either in the displacement of the primary tumor or the lymph nodes. In specific individual cases, large changes, either in volume, up to $50 \%$, or in position, displacement up to $1.6 \mathrm{~cm}$, of the primary tumor are observed that are not a surrogate for the changes in the lymph nodes. Hence, predicting the volumetric or positional changes of the involved lymph nodes is not possible based on primary tumor characteristics. This study shows that the use of image guidance procedures based solely on the primary tumor may lead to correction strategies that might impair the accuracy of the overall treatment that includes the irradiated lymph nodes.

\section{REFERENCES}

1. Kupelian PA, Ramsey C, Meeks SL, et al. Serial megavoltage CT imaging during external beam radiotherapy for nonsmall-cell lung cancer: Observations on tumor regression during treatment. Int J Radiat Oncol Biol Phys 2005;63: 1024-1028.

2. Fox J, Ford E, Redmond K, et al. Quantification of tumor volume changes during radiotherapy for non-small-cell lung cancer. Int J Radiat Oncol Biol Phys 2009;74:341-348.

3. Feng M, Kong FM, Gross M, et al. Using fluorodeoxyglucose positron emission tomography to assess tumor volume during radiotherapy for non-small-cell lung cancer and its potential impact on adaptive dose escalation and normal tissue sparing. Int $J$ Radiat Oncol Biol Phys 2009;73:1228-1234.

4. Bosmans G, van Baardwijk A, Dekker A, et al. Time trends in nodal volumes and motion during radiotherapy for patients with stage III non-small-cell lung cancer. Int J Radiat Oncol Biol Phys 2008;71:139-144.

5. Bosmans G, van Baardwijk A, Dekker A, et al. Intra-patient variability of tumor volume and tumor motion during conventionally fractionated radiotherapy for locally advanced nonsmall-cell lung cancer: A prospective clinical study. Int J Radiat Oncol Biol Phys 2006;66:748-753.

6. Siker ML, Tome WA, Mehta MP. Tumor volume changes on serial imaging with megavoltage CT for non-small-cell lung cancer during intensity-modulated radiotherapy: How reliable, consistent, and meaningful is the effect? Int J Radiat Oncol Biol Phys 2006;66:135-141.

7. Sonke JJ, Lebesque J, van Herk M. Variability of four-dimensional computed tomography patient models. Int J Radiat Oncol Biol Phys 2008;70:590-598.

8. Chang J, Mageras GS, Yorke E, et al. Observation of interfractional variations in lung tumor position using respiratory gated and ungated megavoltage cone-beam computed tomography. Int J Radiat Oncol Biol Phys 2007;67:1548-1558.

9. Underberg RW, Lagerwaard FJ, van Tinteren H, et al. Time trends in target volumes for stage I non-small-cell lung cancer after stereotactic radiotherapy. Int J Radiat Oncol Biol Phys 2006;64:1221-1228.

10. De Ruysscher D, Wanders S, van Haren E, et al. Selective mediastinal node irradiation based on FDG-PET scan data in patients with non-small-cell lung cancer: A prospective clinical study. Int J Radiat Oncol Biol Phys 2005;62:988-994.

11. Spoelstra FO, Pantarotto JR, van Sörnsen de Koste JR, et al. Role of adaptive radiotherapy during concomitant chemoradio- therapy for lung cancer: analysis of data from a prospective clinical trial. Int J Radiat Oncol Biol Phys 2009;75:1092-1097.

12. Pantarotto JR, Piet AH, Vincent A, et al. Motion analysis of 100 mediastinal lymph nodes: Potential pitfalls in treatment planning and adaptive strategies. Int J Radiat Oncol Biol Phys 2009;74:1092-1099.

13. van Baardwijk A, Bosmans G, Bentzen SM, et al. Radiation dose prescription for non-small-cell lung cancer according to normal tissue dose constraints: An in silico clinical trial. Int $J$ Radiat Oncol Biol Phys 2008;71:1103-1110.

14. van Baardwijk A, Bosmans G, Boersma L, et al. Individualized radical radiotherapy of non-small-cell lung cancer based on normal tissue dose constraints: A feasibility study. Int J Radiat Oncol Biol Phys 2008;71:1394-1401.

15. Wu J, Lei P, Shekhar R, et al. Do tumors in the lung deform during normal respiration? An image registration investigation. Int J Radiat Oncol Biol Phys 2009.

16. Gillham C, Zips D, Ponisch F, et al. Additional PET/CT in week 5-6 of radiotherapy for patients with stage III non-small cell lung cancer as a means of dose escalation planning? Radiother Oncol 2008;88:335-341.

17. Woodford C, Yartsev S, Dar AR, et al. Adaptive radiotherapy planning on decreasing gross tumor volumes as seen on megavoltage computed tomography images. Int J Radiat Oncol Biol Phys 2007;69:1316-1322.

18. Schutze C, Bergmann R, Yaromina A, et al. Effect of increase of radiation dose on local control relates to pre-treatment FDG uptake in FaDu tumours in nude mice. Radiother Oncol 2007; 83:311-315.

19. Aerts HJ, van Baardwijk AA, Petit SF, et al. Identification of residual metabolic-active areas within individual NSCLC tumours using a pre-radiotherapy (18)FluorodeoxyglucosePET-CT scan. Radiother Oncol 2009;91:386-392.

20. Abramyuk A, Tokalov S, Zophel K, et al. Is pre-therapeutical FDG-PET/CT capable to detect high risk tumor subvolumes responsible for local failure in non-small cell lung cancer? Radiother Oncol 2009;91:399-404.

21. Yeung AR, Li JG, Shi W, et al. Tumor localization using conebeam CT reduces setup margins in conventionally fractionated radiotherapy for lung tumors. Int J Radiat Oncol Biol Phys 2009;74:1100-1107.

22. Bissonnette JP, Purdie TG, Higgins JA, et al. Cone-beam computed tomographic image guidance for lung cancer radiation therapy. Int J Radiat Oncol Biol Phys 2009;73:927-934. 